\title{
Pelatihan Aplikasi Data Kependudukan dan Surat Menyurat di Desa Jada Bahrin
}

\author{
Boy Dian Anugra Sandy*1, Endang Setyawati Hisyam², Yayuk Apriyanti³, Indra Gunawan, M. Fikri \\ Radiyan $^{5}$ \\ 1,2,3,4,5Program Studi Teknik Sipil, Fakultas Teknik, Universitas Bangka Belitung \\ Desa Balunijuk, Kec. Merawang, Kab. Bangka, Provinsi Kepulauan Bangka Belitung 33172 \\ Telepon (0717) 4260034, 422145, Faksimile (0717) 421303 \\ *e-mail: boyanugra13@gmail.com
}

\begin{abstract}
Jada Bahrin is a village that is very different from other villages in Bangka Island which is famous for its tin mines. This village is famous for its plantations and agriculture. Because the location of the village is in the area of plantations and agriculture, so many village officials or school administrators do not know or are unable to enter data into computers, both population data and write letters. Based on the situation analysis that has been explained, a problem that can be formulated in Jada Bahrin Village is the absence of training for the community to be able to use population applications and correspondence. With this training it is hoped that the village administration and the school can be better and easier to do archiving and data searching.
\end{abstract}

Keywords: Jada Bahrin Village, Population Data Application, Write letters

\begin{abstract}
Abstrak
Jada Bahrin merupakan desa yang sangat berbeda dengan desa lain yang ada di Pulau Bangka yang terkenal dengan tambang timahnya. Desa ini terkenal dengan perkebunan dan pertaniannya. Karena lokasi desa berada di wilayah perkebunan dan pertanian sehingga perangkat desa atau admin sekolah banyak yang belum tahu atau belum bisa melakukan pemasukan data ke komputer, baik data penduduk maupun surat menyurat. Berdasarkan analisis situasi yang telah dijelaskan, dapat dirumuskan suatu masalah yang terdapat di Desa Jada Bahrin yaitu belum adanya pelatihan bagi masyarakat untuk bisa menggunakan aplikasi kependudukan dan surat menyurat. Dengan adanya pelatihan ini diharapkan administrasi desa maupun sekolah bisa lebih baik dan memudahkan untuk melakukan pengarsipan dan pencarian data.
\end{abstract}

Kata kunci: Desa Jada Bahrin, Aplikasi Data Kependudukan, Surat Menyurat

\section{PENDAHULUAN}

Jada Bahrin adalah Desa yang berada di Kecamatan Merawang, Kabupaten Bangka, Provinsi Kepulauan Bangka Belitung. Kecamatan Merawang mempunyai luas wilayah 207,27 $\mathrm{Km}^{2}$ yang terdiri dari 10 Desa. Salah satunya adalah Desa Jada Bahrin yang mempunyai luas wilayah $56 \mathrm{Km}^{2}$. Total jumlah penduduk di Desa Jada Bahrin sebanyak 1.724 jiwa yang terdiri dari 905 laki-laki dan 819 perempuan (Badan Pusat Statistik, 2018). Masyarakat Desa Jada Bahrin mayoritas berprofesi sebagai petani. Salah satu hasil produksi perkebunan dan pertanian Desa Jada Bahrin adalah lada.

Dengan jumlah penduduk yang cukup banyak sudah seharusnya Desa Jada Bahrin mempunyai tata kelola administrasi kependudukan yang memadai dan terkomputerisasi dengan menggunakan aplikasi. Kependudukan itu sendiri adalah hal yang berkaitan dengan jumlah, ciri utama, pertumbuhan, persebaran, mobilitas, penyebaran, kualitas, kondisi, kesejahteraan yang menyangkut politik, ekonomi, sosial, budaya, agama, serta lingkungan penduduk tersebut. (Lestari, 2014). Pengertian lain menurut ilmu sosiologi penduduk adalah kumpulan manusia yang menempati wilayah geografi dan ruang tertentu (Kusumawati, 2014).

Sejalan dengan arah perkembangan Teknologi Informasi maka pengelolaan data penduduk sebagai subsistem dari administrasi kependudukan yang perlu ditata dengan sebaikbaiknya agar dapat memberikan manfaat dalam perbaikan pemerintahan dan pembangunan. 
(Muttaqien, 2014). Menurut Rossa (2015), Aplikasi atau perangkat lunak adalah perintah program komputer yang bila dieksekusi memberikan fungsi dan unjuk kerja seperti yang diinginkan. Struktur data yang memungkinkan program memanifulasi informasi secara profesional dan dokumen yang mengambarkan operasi dan kegunaan program. Aplikasi data kependudukan merupakan aplikasi yang sangat penting, karena kebutuhan akan informasi yang cepat dan akurat mengenai data penduduk yang ada. Banyaknya data yang dikelola dan perlunya penyampaian Informasi yang cepat dalam kegiatan pelayanan administrasi kependudukan di tiap daerah. Instansi pemerintah perlu mengikuti perkembangan teknologi dan terus meningkatkan kemampuannya dalam mengelola data-data yang lebih maksimal (Merzalino, 2013).

Berdasarkan Keputusan Presiden Nomor 52 tahun 1977 tentang pendaftaran penduduk ditujukan untuk membangun sistem pencatatan yang berlaku menyeluruh dan seragam di wilayah Indonesia. Karena pelayanan publik berkaitan erat dengan kepentingan publik. Masyarakat berharap agar penyelenggara pelayanan publik bisa melayani penuh kejujuran, tepat, dan bisa dipertanggungjawabkan kepada publik. (ardiansah, 2019). Di Desa Jada Bahrin pendaftaran dan pengelolaan data penduduk telah dilakukan hanya saja masih dilakukan secara manual yaitu dengan pencatatan data penduduk berdasarkan beberapa pengelompokkan kategori, yaitu pengelompokkan berdasarkan akta lahir, data Kartu Tanda Penduduk, data kartu keluarga (KK), dan lain-lain.

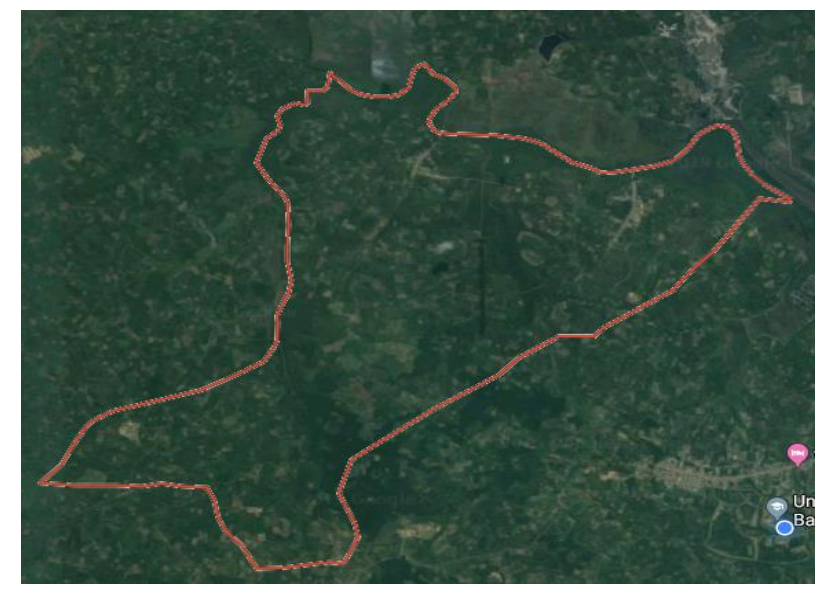

Gambar 1. Peta Desa Jada Bahrin

Berdasarkan analisis situasi yang telah dijelaskan, dapat dirumuskan suatu masalah yang terdapat di Desa Jada Bahrin yaitu: Belum adanya penyuluhan maupun pelatihan mengenai pentingnya pengolahan data kependudukan dan surat menyurat di Desa Jada Bahrin. Untuk itu kami mengadakan pengabdian kepada msayarakat di Desa Jada Bahrin dengan melakukan pelatihan aplikasi data kependudukan dan surat menyurat. Beberapa pengabdian yang telah dilakukan memperoleh hasil positif dalam pengelolaan data kependudukan. Aplikasi Pencatatan Data Kependudukan Akan memudahkan penduduk serta pegawai dalam menginput dan mengolah data kependudukan yakni, data KK, data kelahiran, data kematian, data pindah, dan data datang serta menyajikan informasi laporan data penduduk yang akan dapat digunakan oleh kelurahan akan memudahkan penduduk serta pegawai kelurahan dalam (Ibrahim, 2016). Kegiatan Iptek Tepat Guna bagi Masyarakat berupa sosialisai data kependudukan dapat membantu masyarakat di Desa dalam pencatatan data peristiwa kependudukan yang lebih baik dan akurat (Apiati, 2016). Sistem pengelolaan data kependudukan yang dikembangkan oleh tim IbM mengakomodasi kebutuhan user yaitu staf dalam mengelola data mutasi kependudukan (Suprayogi, 2017). Diharapkan dengan adanya pelatihan aplikasi data kependudukan dan surat menyurat ini nantinya perangkat desa maupun admin di sekolah di Desa Jada Bahrin dapat menggunakan aplikasi komputer untuk penginputan data maupun surat menyurat. Sehingga 
nantinya data yang telah dimasukan maupun kegiatan surat menyurat dapat digunakan dengan maksimal.

\section{METODE}

Sebelum dilakukan pelatihan aplikasi data kependudukan terlebih dulu dilakukan pengupulan data dari Desa Jada Bahrin melalui perangkat desa yang ada. Metode pengumpulan data yang digunakan ada 3 macam, yaitu:

\section{Wawancara}

Data yang dikumpulkan yaitu diperoleh dengan cara melalukan tanya jawab langsung kepada perrangkat desa di kantor Desa Jada Bahrin Kecamatan Merawang Kabupaten Bangka yang berkaitan dengan masalah yang ada di Desa Jada Bahrin.

\section{Dokumentasi}

Pencarian data ini dilakukan dengan mengintip dan memperhatikan data yang diperoleh baik arsip dan lain-lainnya arsip yang ada di kantor Desa Jada Bahrin.

\section{Studi pustaka}

Studi pustaka dilakukan dengan cara mempelajari teori-teori literatur dari jurnal yang berhubungan dengan objek pengabdian sebagai bahan atau dasar pemecahan masalah.

Kegiatan pengabdian masyarakat yang berupa pelatihan ini dilaksanakan di Desa Jada Bahrin, Kecamatan Merawang, Kabupaten Bangka, Provinsi Kepulauan Bangka Belitung. Pelatihan dilakukan selama satu hari dimana peserta akan mendapatkan materi dan aplikasi.. Secara rinci kegiatan pengabdian yang akan dilakukan sebagai berikut :

1. Survei dan penentuan waktu dan tempat kegiatan pelaksanaan bekerjasama dengan Desa Jada Bahrin.

2. Mengundang perangkat desa dan admin di wilayah Desa Jada Bahrin

3. Penyampaian materi pelatihan

4. Praktik menggunakan Aplikasi data kependudukan

Adapun Alat yang mendukung kegiatan ini di antaranya adalah :

1. Perangkat komputer / laptop

2. Infocus

3. Aplikasi Data Kependudukan

\section{HASIL DAN PEMBAHASAN}

Dalam pelaksanaan kegiatan pengabdian kepada masyarakat yang dilakukan di Desa Jada Bahrin, Kecamatan Merawang, Kabupaten Bangka, Provinsi Kepulauan Bangka Belitung pada hari Selasa tanggal 24 September 2019. Pengabdian kepada masyarakat ini dimulai dengan kegiatan awal yaitu sambutan dari Ketua Jurusan Teknik Sipil Universitas Bangka Belitung yang menerangkan mengenai kegiatan pengabdian masyarakat yang mengambil judul pelatihan aplikasi data kependudukan dan surat menyurat di Desa Jada Bahrin. Kemudian dilanjutkan dengan sambutan dari Kepala Desa Jada Bahrin. Pada kegiatan inti yaitu pemateri menyampaikan materinya mengenai data kependudukan dan aplikasi nya. Dilanjutkan dengan praktik menggunakan aplikasi data penduduk dan surat menyurat, para peserta maju satu persatu mewakili instansinya masing-masing. 


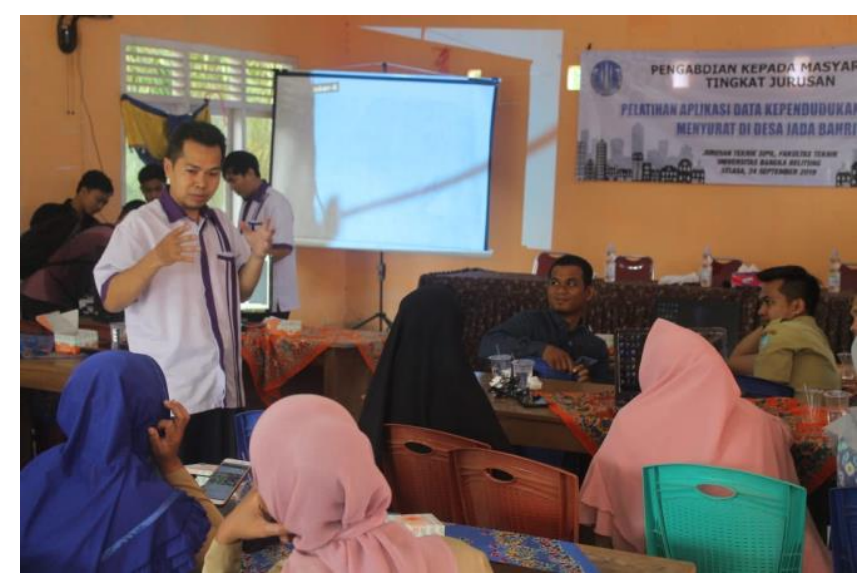

Gambar 2. Penyampaian Materi

Dalam menyampaikan materi, pemateri menjelaskan secara langsung pentingnya data dan surat menyurat. Dengan bantuan aplikasi dalam komputer/laptop dapat memudahkan pekerjaan tersebut. Materi yang disampaikan oleh pemateri membahas 2 point yaitu data penduduk dan surat menyurat pada aplikasi di komputer. Hal ini bertujuan agar para peserta bisa memahami langsung hal-hal yang dianggap bisa digunakan dalam pekerjaan mereka seharihari.

Pada saat penyampaian materi langsung dilakukan juga sesi tanya jawab untuk para peserta. Peserta sangat antusias dalam bertanya tentang bagaimana cara pemasukan data aplikasi dan bagaimana mengolah data serta membuat surat menyurat yang baik.

Kegiatan berikutnya para peserta dipersilahkan maju satu persatu berinteraksi langsung dengan pemateri dengan menggunakan komputer yang telah disediakan dan di install aplikasi data kependudukan. Disini pemateri menunjukan secara langsung proses penginputan data penduduk ke aplikasi dan juga format untuk pemasukan data, serta keluaran dari data yang telah dimasukan tadi. baik untuk data penduduk maupun untuk pembuatan surat.

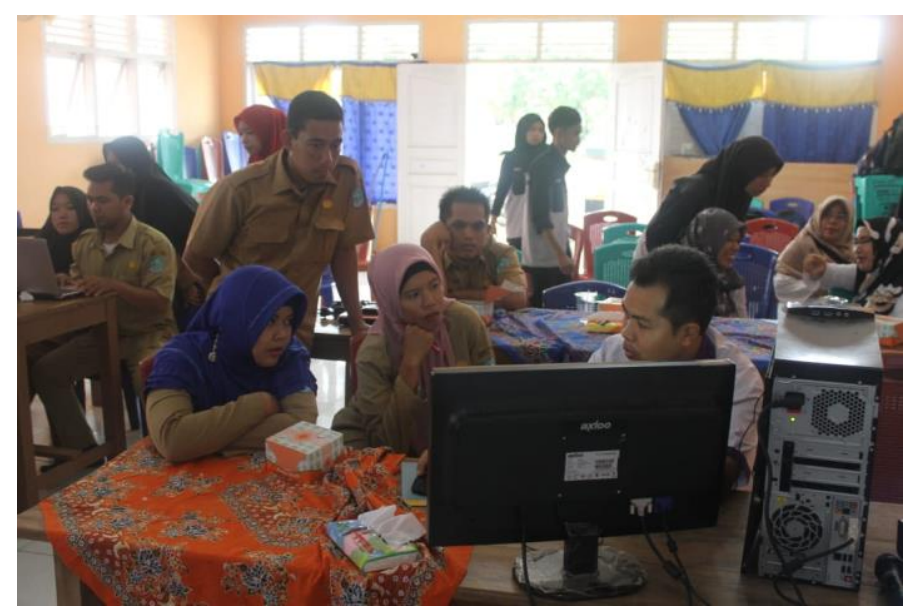

Gambar 3. Pelatihan kepada perangkat desa 


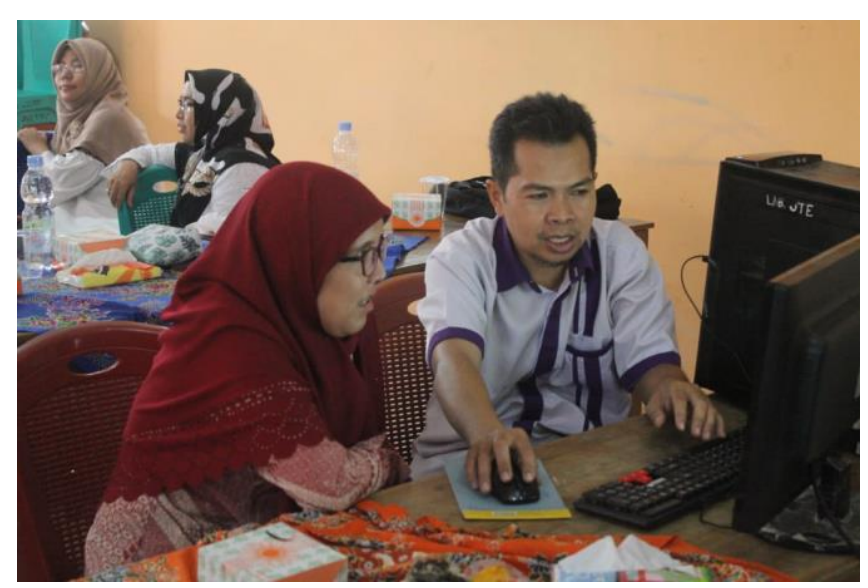

Gambar 4. Pelatihan kepada perwakilan Pondok Pesantren

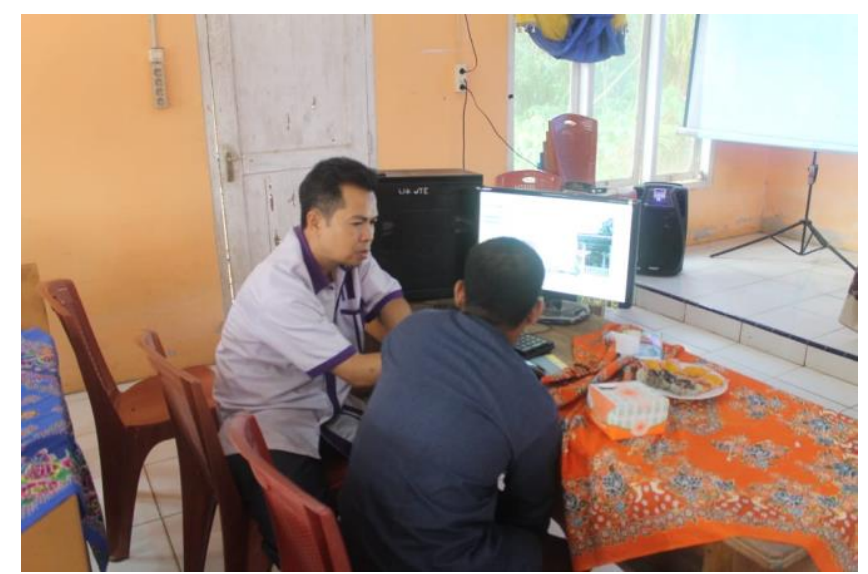

Gambar 5. Pelatihan kepada perwakilan Sekolah Dasar

Setelah mendapat pelatihan aplikasi data kependudukan dan surat menyurat, para peserta mencoba memasukan data penduduk dan mencoba untuk membuat surat. Berikut ini tampilan dari menu penginputan data pada aplikasi dan hasil luarannya nya.

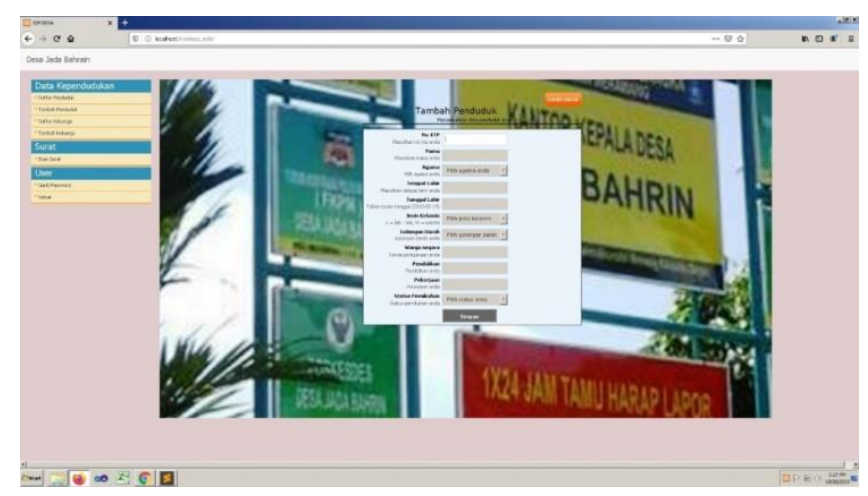

Gambar 6. Tampilan Menu Input Data Penduduk 


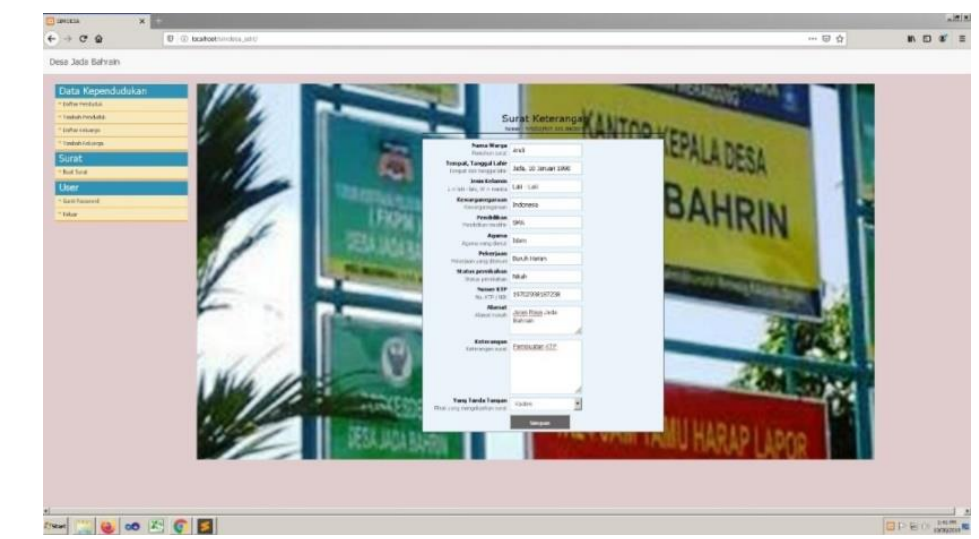

Gambar 7. Tampilan Menu Input Data Untuk Surat Menyurat

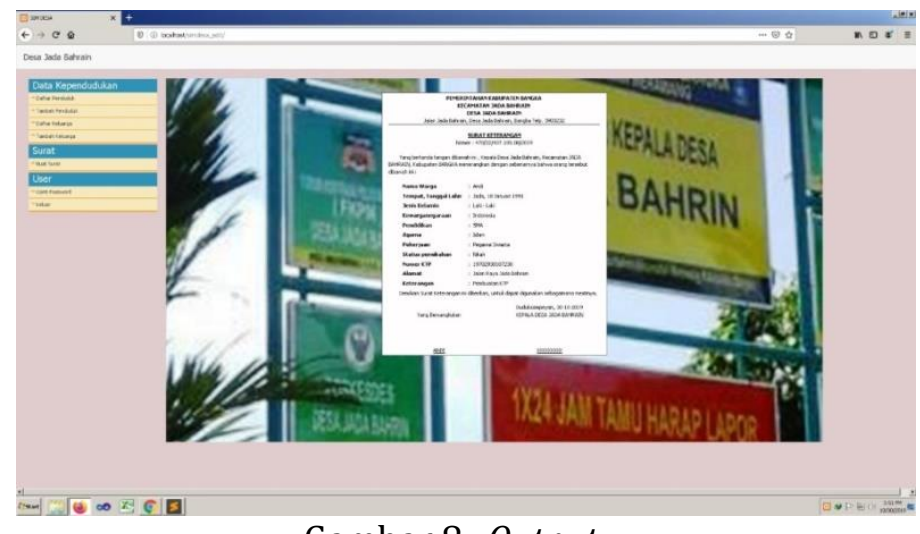

Gambar 8. Output

Adapun hasil yang diperoleh dari pengabdian ini berupa pembagian aplikasi data kependudukan dan surat menyurat kepada perangkat desa dan instansi di wilayah Desa Jada Bahrin. Mengajarakan cara pengelolaan data penduduk dan pembuatan surat menyurat pada perangkat desa dan admin sekolah di Desa Jada Bahrin. Dengan adanya pelatihan aplikasi pengelolaan data penduduk ini dapat membantu pekerjaan perangkat desa dalam mengisi dan mencari data penduduk serta surat menyurat di Desa Jada Bahrin.

\section{KESIMPULAN}

Kesimpulan dari pengabdian kepada masyarakat ini adalah Aplikasi Data Kependudukan dan Surat Menyurat di Desa Jada Bahrin dapat mempermudah perangkat desa dan admin sekolah dalam memasukan data, mengelola data, mencari data penduduk, dan membuat surat di Desa Jada Bahrin.

\section{UCAPAN TERIMA KASIH}

Penulis mengucapkan terima kasih kepada Universitas Bangka Belitung dan LPPM yang telah memberi dukungan financial terhadap pengabdian ini.

\section{DAFTAR PUSTAKA}

Apiati, Vepi. dkk. (2016). Sosialisasi Micro Sistem Data Kependudukan Untuk Membantu Kelurahan Sukamanah Dalam Mencatat Data Peristiwa Penduduk. Jurnal Siliwangi. Seri Pengabdian Kepada Masyarakat. 2(2), 132-136

Ardiansah. dkk. (2019). Penyelenggaraan Pelayanan Publik Berdasarkan Undang-Undang Tentang Pelayanan Publik Di Kecamatan Mempura Kabupaten Siak. Jurnal Dinamisia. 3(2), 368-377

Badan Pusat Statistik. (2018). Kecamatan Merawang Dalam Angka 2018. 978-602-1023-69-3

Ibrahim, Ali. dkk. (2016). Rancang Bangun Aplikasi Pencatatan Data Kependudukan Kelurahanpahlawan Berbasis Web. Jurnal Sistem Informasi. 8(1), 947-957 
Keputusan Presiden No.52 Tahun 1977. Pendaftaran Penduduk. Jakarta.

Kusumawati, T. (2014). Sistem Informasi Pendataan Penduduk Dilengkapi Dengan Sms Gateway Sebagai Media Penyampaian Informasi Pada Kantor Kelurahan Desa Kotesan. AMIKOM. Yogyakarta.

Lestari, S. (2014). Analisis Dan Perancangan Sistem Informasi Pengolahan Data Penduduk Di Kantor Kecamatan Sungaiselan Bangka Tengah. Stmik Atma Luhur. Pangkalpinang.

Merzalino. (2013). Aplikasi Pengolahan Data Kependudukan Di Kecamatan Lawang Kidul Tanjung Enim Menggunakan Borland Delphi 2007 dan SQL Server 2008. POLITEKNIK PalComTech. Palembang.

Muttaqien. (2014). Analisis Dan Perancangan Sistem Informasi Kependudukan Pada Pemerintah Desa Bangunjiwo Berbasis WEB. STMIK AMIKOM. Yogyakarta.

Rossa. (2015). Rekayasa Perangkat Lunak Terstruktur \& Berorientasi Objek. Bandung: Informatika Bandung.

Suprayogi. dkk. (2017). Pengelolaan Data Kependudukan Kelurahan Krobokan Semarang. Jurnal Pengabdian Masyarakat Wikrama Parahita 1(1), 1-4 